IZA DP No. 6731

Ethnic Diversity and Team Performance:

A Field Experiment

Sander Hoogendoorn

Mirjam van Praag

July 2012 


\title{
Ethnic Diversity and Team Performance: A Field Experiment
}

\author{
Sander Hoogendoorn \\ University of Amsterdam \\ Mirjam van Praag \\ University of Amsterdam \\ and IZA
}

\section{Discussion Paper No. 6731 \\ July 2012}

IZA
P.O. Box 7240
53072 Bonn
Germany

Phone: +49-228-3894-0
Fax: +49-228-3894-180
E-mail: iza@iza.org

Any opinions expressed here are those of the author(s) and not those of IZA. Research published in this series may include views on policy, but the institute itself takes no institutional policy positions.

The Institute for the Study of Labor (IZA) in Bonn is a local and virtual international research center and a place of communication between science, politics and business. IZA is an independent nonprofit organization supported by Deutsche Post Foundation. The center is associated with the University of Bonn and offers a stimulating research environment through its international network, workshops and conferences, data service, project support, research visits and doctoral program. IZA engages in (i) original and internationally competitive research in all fields of labor economics, (ii) development of policy concepts, and (iii) dissemination of research results and concepts to the interested public.

IZA Discussion Papers often represent preliminary work and are circulated to encourage discussion. Citation of such a paper should account for its provisional character. A revised version may be available directly from the author. 


\section{ABSTRACT}

\section{Ethnic Diversity and Team Performance: A Field Experiment ${ }^{\star}$}

One of the most salient and relevant dimensions of team heterogeneity is ethnicity. We measure the causal impact of ethnic diversity on the performance of business teams using a randomized field experiment. We follow 550 students who set up 45 real companies as part of their curriculum in an international business program in the Netherlands. We exploit the fact that companies are set up in realistic though similar circumstances and that we, as outside researchers, had the unique opportunity to exogenously vary the ethnic composition of otherwise randomly composed teams. The student population consists of $55 \%$ students with a non-Dutch ethnicity from 53 different countries of origin. We find that a moderate level of ethnic diversity has no effect on team performance in terms of business outcomes (sales, profits and profits per share). However, if at least the majority of team members is ethnically diverse, then more ethnic diversity has a positive impact on the performance of teams. In line with theoretical predictions, our data suggest that this positive effect could be related to the more diverse pool of relevant knowledge facilitating (mutual) learning within ethnically diverse teams.

JEL Classification: J15, L25, C93, L26, M13, D83

Keywords: ethnic diversity, team performance, field experiment, entrepreneurship, (mutual) learning

Corresponding author:

Mirjam Van Praag

Amsterdam School of Economics

University of Amsterdam

Roetersstraat 11

1018 WB Amsterdam

The Netherlands

E-mail: c.m.vanpraag@uva.nl

\footnotetext{
* We are grateful to the department of international business studies of the Amsterdam College of Applied Sciences for their support in carrying out this research. We thank Hessel Oosterbeek, Suncica Vujic and seminar participants in Amsterdam, Potsdam and Utrecht for their comments and suggestions. We acknowledge financial support from the Dutch Ministry of Economic Affairs. The usual disclaimer applies.
} 


\section{Introduction}

It is impossible to pick up a business publication these days without reading about the wonders of teamwork. [...] Once teamwork is accepted as a basic business principle, it is not much of a stretch to think about teams that are comprised of diverse individuals, coming from different countries and cultures. (Lazear, 1999, p. 15)

We measure the causal effect of ethnic diversity on the performance of business teams using a randomized field experiment. The choice for this topic and approach are easily motivated. Teams have become increasingly important as decision making bodies. This is the case in many sorts of organizations, varying from judges in collegial courts or academic researchers to business start-ups (Hamilton et al., 2003). Consequently, the effective composition or diversity of teams has become an interesting topic of research (Prat, 2002; Hoogendoorn et al., 2011).

One of the most salient dimensions of team heterogeneity is ethnicity (Alesina and La Ferrara, 2005). Ethnic diversity implies heterogeneity in (mother) languages, religions, races and cultures (Alesina and La Ferrara, 2005). It is commonly measured based on country of birth, of the individual or of his/her parents. It coincides with a variety of norms, information sets, knowledge and ability levels (Lazear, 1999; Morgan and Vardy, 2009). This variety affects the formation and performance of teams. Ethnic diversity would benefit team performance due to a more diverse pool of skills and knowledge that leads to complementaries and mutual learning. For example, due to complementarities and learning opportunities, ethnically diverse teams are associated with more creativity and innovation (Alesina and La Ferrara, 2005; Lee and Nathan, 2011; Ozgen et al., 2011b). On the other hand, the costs associated with more ethnic diversity would be related to more difficult communication and coordination (Lazear, 1999; Morgan and Vardy, 2009). ${ }^{1}$ All in all, ethnic diversity is an influential source of heterogeneity.

Ethnic diversity is highly relevant in an increasingly globalized world. Multinational firms often staff teams internationally and local populations -especially in big cities- become more mixed and multicultural. Ethnic diversity is a current fact of life and the share of ethnic minorities in Western populations is increasing sharply (Lazear, 1999; Alesina and La Ferrara, 2005; Ozgen et al., 2011b). In the United States, for example, the share of minorities is expected to rise from about one-third to roughly the majority in 2042 (Bernstein and Edwards, 2008). As a consequence, it is likely that any team in the workplace will become more and more diverse in terms of ethnicity, even if the optimal team formation would indicate otherwise.

The relevance and potential impact of ethnic diversity in teams motivate our choice for the topic of this study. Our approach of a randomized field experiment among business

\footnotetext{
${ }^{1}$ Ethnic diversity may also affect group formation and performance through its influence on the group culture (Earley and Mosakowski, 2000; Richard et al., 2004) and the strategic behavior of individual team members (Alesina and La Ferrara, 2005).
} 
teams that start up in identical circumstances is motivated based on the literature. Team formation is obviously driven by prospective productive consequences. If the situation carries a higher likelihood that an ethnically diverse team is beneficial, the team composition will be more mixed (Boisjoly et al., 2006). Hence, the measured effects of diversity on performance in real-world teams are likely to be biased due to endogenous team composition. Examples of studies conducted on teams in real organizations include Hamilton et al. (2004), Leonard and Levine (2006), Carter et al. (2010) and Parrotta et al. (2010), and their results are ambiguous (Alesina and La Ferrara, 2005). ${ }^{2}$

Laboratory experiments do not suffer from endogenous team composition. Experiments in the lab have established results that are largely consistent with the theory proposed by Lazear (1999). An optimal degree of heterogeneity results from the trade-off between the benefits of more diversity and the associated increased costs of communication and coordination (Alesina and La Ferrara, 2005). The downside of laboratory studies is that their resemblance to real-world situations may be limited. Moreover, they typically measure short-term effects, whereas the consequences of a team's diversity in terms of, for example, coordination, communication, complementarities and learning are not likely to become evident instantaneously (Boisjoly et al., 2006). It is thus useful to study the effects of team composition in the longer run and preferably in more realistic circumstances.

Indeed, some studies measuring the effect of ethnic diversity have tried to combine the advantages of studies in real organizations with experimental studies by carrying out field or 'quasi' experiments. Hansen et al. (2006) resemble the design of a field experiment. They measure the impact of demographic diversity (age, gender and ethnicity) in student groups of four to five students on the team's academic performance and find no effect. ${ }^{3}$ Boisjoly et al. (2006) find that attitudes and behaviors change when people of different ethnicity are randomly assigned to live together at the start of their first year of college. White students assigned to African-American roommates show to be significantly more empathetic to these groups.

We conclude that measurements of the causal effect of a team's ethnic diversity on its performance are scarce, especially in the longer run. This kind of measurement is the objective of our study. To this end, we conducted a randomized field experiment in the context of a compulsory entrepreneurship program for undergraduate students in international business at the Amsterdam University of Applied Sciences. We follow 550 students who set up and manage 45 real companies as part of their curriculum in the academic year 2008-2009. We exploit the fact that the -otherwise homogeneous- population

\footnotetext{
${ }^{2}$ Other studies examine the effects of ethnic diversity on productivity at the country (Montalvo and Reynal-Querol, 2005), region (Ozgen et al., 2011a) or city level (Ottaviano and Peri, 2006; Lee and Nathan, 2011). Related are also studies measuring the impact of ethnic composition of schools or neighborhoods on educational outcomes (e.g., Hoxby, 2000; Angrist and Lang, 2004; Card and Rothstein, 2007; Hanushek et al., 2009; Aslund et al., 2011).

${ }^{3}$ Group composition is random and no exogenous stratification is imposed. Teams are required to select one of three contract forms that determine the authority of grading. The drawback of this design, when interested in the bare effect of ethnic diversity on team performance, is that the effect of interest may be confounded by the contract choice (that may be related to ethnic diversity).
} 
consists of $55 \%$ students with a non-Dutch ethnicity from 53 different countries of origin and that we, as outside researchers, were allowed to exogenously vary the ethnic composition of otherwise randomly composed teams. The resulting percentage of students with a nonDutch ethnicity per team varies from $20 \%$ to $90 \%$. We use a rather common definition of ethnicity, i.e., parents' country of birth.

Our randomized field experiment implies a level of controlled circumstances comparable to the laboratory. All teams start up companies at the same time and under equal circumstances and all members are selected from a pool of students, minority or Dutch, of the same caliber. The substantial variation (20-90\%) enables us to capture possible non-linearities in the relationship between ethnic diversity and team performance. On the other hand, the entrepreneurship program and the truly joint task with strong incentives to maximize shareholder value of a company in a real market resemble realistic circumstances that are not likely to be mimicable in a laboratory setting. In particular, these circumstances give rise to the formation of a real team in which people have time to establish roles and observations of other team members.

What kind of results might we expect? We combine Lazear's argument (1999) that there is a trade-off between the costs and benefits of an ethnically more diverse team with recent insights from Earley and Mosakowski (2000) and Richard et al. (2004) based on Blau's theory of heterogeneity (1977). The non-formal models in these studies refine Lazear's argument by allowing the costs of communication and coordination to be a non-linear function of ethnic diversity. Moderately heterogeneous teams would incur higher costs of communication and coordination than teams that are homogeneous or heterogeneous in terms of ethnicity. In these moderately heterogeneous teams subgrouping along ethnic lines may have negative effects such as distrust, conflicts or stereotyping between distinct subgroups. ${ }^{4}$

The non-linear relationship between communication costs and ethnic diversity could perhaps be illustrated by considering three team compositions: (i) with a low percentage of minorities, (ii) with a substantial subgroup of minorities, and (iii) with a majority group of minorities. In the first situation the communication costs are probably low. The few minorities present will perhaps not participate in the team process and be left aside. This is costly in the sense that their productivity is lost, but communication can be low cost too and based on habits, language and norms of the majority group (i.e., with a single identity). In the second situation the group that may not take part in the productive process of the majority is larger. Segregated subgroups may be formed by the majority and the others with distinct manners of work. Hence, the cost of diversity at this stage is higher. In the third situation, in a truly ethnically diverse team, the costs of communication

\footnotetext{
${ }^{4}$ Akerlof and Kranton (2005) show that teams' identity could act as a substitute mechanism for formal incentive schemes. In a series of laboratory experiments, Charness et al. (2007) find that group membership, and identification with this group, influence individual behavior in strategic environments. Moreover, individuals tend to operate significantly more altruistically towards ingroup members than to outgroup individuals (Chen and Li, 2009). In a field experimental setting, Dugar and Shahriar (2010) find that group identity can reduce moral hazard problems.
} 
have probably become lower due to the absence of subgroups and the desirability for every team member to participate in a hybrid team culture with a diverse identity (Earley and Mosakowski, 2000; Richard et al., 2004).

We thus expect that the costs of ethnic diversity follow an inverse U-shaped pattern, whereas the benefits of complementarities and mutual learning may be an(y) increasing function of ethnic diversity (Lazear, 1999). However, due to the fact that we do not have any conjectures about the specific forms of the cost and benefit functions relative to each other, the net effect of ethnic diversity on team performance remains a question that needs to be answered empirically.

Our empirical analysis renders the following results. The impact of a team's ethnic diversity on its performance in terms of sales, profits and profits per share is positive, although only starting at a certain turning point at which at least half of the team is ethnically diverse. Before this turning point the relationship is flat or slightly negative. With respect to underlying mechanisms, our data show that more (mutual) learning could explain why ethnic heterogeneous teams achieve better results. Ethnically diverse teams also have a more diverse pool of relevant knowledge facilitating (mutual) learning.

The contribution of our study to the literature is the following. Our randomized field experiment enables us to measure the causal impact of ethnic diversity on team performance in the longer run in a controlled but realistic setting. This setting is characterized by a sample of student teams that start up a real business in similar circumstances. There is substantial exogenous variation in the ethnic diversity of the teams that are otherwise comparable. Finally, questionnaires enable us to measure and assess the validity of various possible underlying mechanisms identified in the literature that could explain the effect of ethnic diversity on team performance.

In what follows, section 2 provides information on the context and design of the experiment. The context and design and therefore parts of these descriptions are similar to the experiment described in Hoogendoorn et al. (2011). In section 3 we describe the data and present results from randomization checks. In section 4 we show the empirical findings. Section 5 discusses and concludes.

\section{Context and design}

\subsection{Context}

The teams in our experiment take part in the Junior Achievement (JA) Young Enterprise Start Up Program, in the US known as the JA company program. This is the worldwide leading entrepreneurship education program in secondary education (US and Europe) and post-secondary education (only Europe). In 2009, almost 10 million students from 123 countries participated in JA-programs on work readiness, financial literacy and entrepreneurship (JA Worldwide annual report, 2009), including more than 3 million students from 38 European countries (JA Europe annual report, 2009).

The entrepreneurship program that we study is a compulsory part of the curriculum of 
international business studies at the Amsterdam College of Applied Sciences. It lasts for an entire academic year and covers about one-fifth of students' first-year undergraduate curriculum in all sub-departments. ${ }^{5}$ Our experiment was conducted in the academic year 2008-2009. ${ }^{6}$ The program requires students to set up and manage a business venture with a team of approximately 10 to 12 fellow students. Students issue shares, appoint officers and delegate tasks, produce and market products or services, keep the accounts and organize shareholders' meetings. Students frequently interact, build up relationships, and create routines and processes to achieve their common goal. In addition, each company is supported by a coach from the business world. Throughout the program the teams report regularly to their professor and business coach who are randomly matched to teams. The companies also pay taxes and social security payments.

Companies generally operate as follows. They start with appointing an interim CEO. Teams then elect officers and delegate tasks among their members. About half of the team works in non-management positions and the other half holds specific management positions including the CEO and CFO. After half a year the management positions are redistributed among the formerly non-managing part of the team. ${ }^{7}$ Right from the beginning teams also start to brainstorm about possible products or services, where promising business ideas are further analyzed by conducting market research. Subsequently, the most viable business idea is selected and developed (there are no restrictions in selecting the type of business activity). Once the corporate plan has been finished, teams start to raise capital and organize a shareholders' meeting. Other sources of funding such as personal or outside loans were prohibited. Business operations start as soon as the majority of shareholders approves the corporate plan. Production and marketing of products or services then become the key activities. At the end of the program all companies are liquidated and teams present their annual report for approval at the final shareholders' meeting. Profits are proportionally divided among the shareholders. Team characteristics such as their size, ethnic composition and the product or service they sell are listed in Table A1 in the Appendix. Our sample includes 45 teams with (initially) 550 students in total, i.e., approximately 12 students per team on average.

\section{Ethnicity}

Students are defined as native or Dutch if both parents are born in the Netherlands, whereas students are considered immigrant, minority or non-Dutch if at least one parent is not born in the Netherlands (see Hartog, 2011). The share of students in our sample

\footnotetext{
${ }^{5}$ The department of international business studies is divided into five sub-departments: management, business management, financial management, trade management Asia and business languages.

${ }^{6}$ We also randomized students into teams based on their gender in the academic year 2008-2009 (see Hoogendoorn et al., 2011). Since gender diversity and ethnic diversity are orthogonal this will not contaminate our results in this paper.

${ }^{7}$ The relationship between the ethnic composition of teams and their allocation of roles across ethnicities is discussed in the next subsection.
} 
with a non-Dutch ethnicity is $0.55 .^{8}$ We measure ethnic diversity dichotomously. This is consistent with previous empirical studies (Hamilton et al., 2004; Boisjoly et al., 2006; Hansen et al., 2006; Carter et al., 2010) as well as with our assignment of students to teams (see next subsection). ${ }^{9}$ Students with a non-Dutch ethnicity are born abroad in $38 \%$ of the cases, with $82 \%$ of the fathers born abroad and $87 \%$ of the mothers. In $69 \%$ of the cases both the father and the mother are born abroad.

Table 1 shows that the students in our sample are from 53 different countries of origin with an average number of approximately 6 different countries of origin per team (panel A). For the purpose of presentation, the descriptive statistics in Panel B are clustered by continent (see Parrotta et al., 2010). They show that ethnic variation among minority students is substantial. Panel $\mathrm{C}$ shows that there are virtually no ethnic clusters at the team level. The vast majority of ethnic minority students has no team members from the same country of origin (70\%), whereas $19 \%$ of the ethnic minority students has only one team member from the same country of origin (the average number of students with a non-Dutch ethnicity per team is approximately 6.8 at the start of the program). Hence, we can safely assume that the share of students with a non-Dutch ethnic background is a true indicator of the team's ethnic diversity. ${ }^{10}$ This varies exogenously and substantively.

$<$ Insert Table 1 about here $>$

\subsection{Design}

One week before the start of the entrepreneurship program, we obtained students' names, gender and field of study from the school administration. Based on students' names we determined their ethnicity, Dutch versus non-Dutch (see Mateos, 2007 for a motivation of this name-based determination). Nearly 90 percent of the name-based classifications matched with students' actual ethnicity that we retrieved through a pretreatment survey one week later. As expected, most of the mismatches in the category of ethnic minority students occured among those with Dutch fathers.

Subsequently, we defined the fractions of ethnic minority students for each team per field of study and assigned students with Dutch and non-Dutch ethnicity randomly to teams according to these fractions. The program coordinators enforced this assignment

\footnotetext{
${ }^{8}$ The average share of minorities in Dutch higher vocational schools is approximately 0.20 , which is close to the population average (Hartog, 2011). The considerably higher share here reflects the international character and student group of this program in the multicultural capital of Amsterdam.

${ }^{9}$ An alternative way of measuring ethnic diversity takes the country of (parental) origin into account and is expressed in terms of Blau's diversity index (1977), $1-\sum_{i=1}^{N} p_{i}^{2}$. Here, $p$ is the share of individuals in a (ethnic) category $i$ and $N$ the number of (ethnic) categories. The downside of Blau's diversity index is that it implicitly assumes that each category is different from another to the same extent. The upside, though, may be that it takes into account that diversity is larger when ethnic minority students originate from all distinct countries than when they or their parents are all born in the same foreign country. However, our initial assignment of students to teams and, hence, the exogenous variation in teams' diversity is based on the dichotomous measure of ethnicity. As a consequence, we can only use that measure convincingly to study the causal effect of ethnic diversity on team performance.

${ }^{10}$ Robustness checks in section 4 indicate that controlling for the number of different countries of origin does not change the main results.
} 
successfully (only six students changed teams during the year). ${ }^{11}$ Figure 1 shows the frequency distribution of the share of minorities per team at baseline, based on the actual ethnic status of students (from the pretreatment survey). The share of minorities which is exogenously imposed and unknown to the students ranges from 0.2 to 0.9 . This substantial variation enables us to study the causal impact of teams' ethnic diversity on their performance. Note that teams with a relatively high share of minorities are actually heterogeneous in terms of ethnicity (due to the limited presence of ethnic clusters within these teams).

\section{$<$ Insert Figure 1 about here $>$}

\section{Composition dynamics}

During the year 104 students (19\%) dropped out. ${ }^{12}$ This reduced the average team size from 12 at the start of the program to 10 at the end. Dropouts did not alter the overall share of minorities or contaminate the design of our experiment. First, the ethnic composition of teams is largely unaffected. The correlation between teams' share of minorities at baseline and at the end is 0.86 . Second, dropout rates do not vary across teams in relation to their ethnic composition. Regression coefficients of the share of minorities at baseline (and its square) when explaining dropout decisions are insignificant.

Companies appoint a management team twice, for the first and second half of the program. Tests indicate that the ethnic diversity of the entire team -on which the treatment is based-is a realistic reflection of the management team (possibly the more influential part of the team). Regressing the share of minorities in the management team on the share of minorities in the entire team returns a coefficient of 0.95 for the first half of the program and 0.97 for the second half. ${ }^{13}$ Moreover, students of non-Dutch ethnicity are not significantly more or less likely to be part of the management team than students of Dutch ethnicity in each of the semesters.

All in all, we are confident that the team dynamics that take place after the initial assignment of students to teams have not contaminated our design.

\section{Incentives}

The program provides various (team and individual) incentives to align students' interests with the business performance of their company. At the indidual level, incentives are generated by the threat of dismissal in case of underperformance. This implies exclusion

\footnotetext{
${ }^{11}$ Neither professors nor students were informed about the nature of the imposed team composition. Professors and students only knew that a research project was conducted which required to stick to the imposed team assignment. Based on interviews with students, we are confident about their uninformedness.

${ }^{12}$ The average dropout rate for first-year students in Dutch higher vocational schools is about $30 \%$ including students that switch study and/or school (HBO-raad, 2010). These rates are commonly high in the Netherlands, where selective admission of students on the basis of grades or achievements is not allowed. For international programs, such as the one studied here, dropout rates are much lower since these programs generally attract students that are more motivated.

${ }^{13}$ These coefficients are similar for median regressions that minimize the effect of possible outliers. F-tests further indicate that none of these coefficients are significantly different from 1.
} 
from the program, a loss of credit points and thus a much lower chance of obtaining an undergraduate degree (that requires a minimum number of credit points in the first year). Dismissal requires two-third of the team members' votes plus the approval of their professor. It is a credible threat: half of the teams experiences at least one dismissal and the average number is 0.73 per team. ${ }^{14}$

Students' grades for the program (20\% of GPA) are determined by both individual and team performance (their weight in the total program grade is about 50/50). An indicator of the considerable weight of individual performance is that the average difference between the highest and lowest grade within a team is 1.3 (on a scale from 1 to 10). The relevance of team performance for students' grades is indicated by the positive correlations between the average grade in the team and business performance in terms of, for example, sales (0.34) or positive profits (0.18).

Team incentives are further provided by a formal business competition. At the end of the program, six selected teams present their results in a 'business pitch' to a jury of entrepreneurs who select a winner based on business outcomes and presentations. The winning team obtains a cup, often gets some (local) press attention and will represent the college in the national competition. In addition, virtually all students own shares of their company. Other shareholders are usually family members, friends or acquaintances.

Reported effort levels in terms of hours are a quantitative reflection of the effectiveness of these incentives. On average, students spend about 8.1 hours per week (s.d. 3.8) on the program, which covers $20 \%$ of their curriculum. This is substantial relative to the 32 hours per week students in Dutch higher vocational schools spend on their education (Allen et al., 2009). The incentives discussed above make it likely that the efforts of students are directed towards the business outcomes we measure.

\section{Data}

Data about teams and individuals was collected through administrative data, teams' annual reports and three extensive surveys. Students filled out a survey at the first day of the academic year (pretreatment, in September 2008), halfway (in January 2009) and at the end of the program (posttreatment, in May 2009). Response rates are respectively $88 \%$, $86 \%$ and $78 \%$. We use the information from the questionnaires for various purposes. Based on this, we check the validity of the name-based assignment of students to ethnicities and the random assignment of students to teams given their ethnic background. Moreover, the questionnaires enable us to relate our findings to and control for individual and team characteristics and processes regarding complementarities, learning, communication and coordination. As we will discuss in Section 4, communication and coordination are proxied by self-assessments of team members about the team's atmosphere and the prevalence of conflicts.

\footnotetext{
${ }^{14}$ The occurrence and number of dismissals are unrelated to both the business performance and the ethnic composition of teams.
} 
Table 2 reports descriptive statistics of individual and team characteristics. The pretreatment survey administers background characteristics such as age, gender and field of study. We also measure the (weighted) grade point average of all courses that students participate in during their first year. ${ }^{15}$ In addition, all three surveys include self-assessments of the knowledge that students have in seven areas relevant for successful entrepreneurship (see Minnitti and Bygrave, 2001; Karlan and Valdivia, 2011). Hence, we can trace the individual development of these knowledge areas during the program as a proxy for learning (reported in Table 2 are knowledge levels at baseline on a scale from 1 to 5). ${ }^{16}$

Business performance metrics are gathered or calculated from the companies' annual reports that we obtained from 43 out of 45 teams (see Table 2). We measure sales, profits and profits per share in euro. We also add a binary indicator of positive profits because students tend to view as the bottom line result whether they are able to satisfy their shareholders. Average sales amount to 841 euro with a standard deviation of 699 euro. Profits are on average negative at -69 euro varying from a loss of 1016 euro to a profit of 477 euro. 22 teams make positive profits, while 21 teams run a loss. Profits per share vary between -15 and +15 euro. ${ }^{17}$

$<$ Insert Table 2 about here $>$

\section{Randomization}

To examine whether students are randomly assigned to teams of different ethnic composition, we regress students' characteristics on the share of minorities in their team, separately for students of Dutch and non-Dutch ethnicity (see Table 3). The first two columns of panel A show that native (Dutch) students who are assigned to teams with many ethnic minority students are somewhat less likely to be female and more likely to study 'trade management Asia'. The last two columns of panel A indicate that ethnic minority students assigned to teams with a high share of minorities are somewhat more likely to be younger and to study 'trade management Asia'. In all other dimensions, the assignment of native (Dutch) and ethnic minority students is random.

In a similar fashion, we examined at the team level whether (average) characteristics of students correlate with the ethnic composition of teams. Panel B shows that ethnic diversity is not systematically related to any of the (average) team characteristics except

\footnotetext{
${ }^{15}$ In order to circumvent possible endogeneity issues we calculate students' GPA using predicted values from a regression of grade point average in the first year on high school track, separately for students of Dutch and non-Dutch ethnicity.

${ }^{16}$ Through standard batteries of questions we also obtain (unreported) validated measures of 'softer' individual characteristics that are associated with entrepreneurship: the 'big five' factor model of personality structure (Goldberg, 1990; Zhao and Seibert, 2006), and entrepreneurial skills and traits such as creativity, market awareness, networking, perseverance, need for achievement and risk aversion (see Parker, 2009; Oosterbeek et al., 2010).

${ }^{17}$ Shares have a nominal value of 20 euro. The mean number of shares issued is 52 (s.d. 21.5). The minimum and maximum numbers of shares sold amount to respectively 15 and 100 . On average, half of the shares are bought by team members themselves. The number of shares and, hence, funding of companies is unrelated to the ethnic diversity of teams.
} 
for the likelihood of studying 'trade management Asia'. Based on the analyses in this subsection we will perform various robustness checks in the next section to test whether any pretreatment differences with regard to the ethnic composition of teams confound the main results.

$<$ Insert Table 3 about here $>$

\section{Results}

\subsection{Main finding}

Table 4 shows the relationship between the share of minorities in a team and four measures of business performance: (ln)sales, profits, the probability of profits being positive and profits per share. Note that a larger share of minorities implies a more ethnically diverse team (due to the different countries of origin of non-Dutch team members). In panel A performance measures are regressed on the share of minorities in the team and its square. A linear specification testing the effect of the share of minorities on business performance turned out insignificant in all specifications. We also tested higher order specifications and these turned out being insignificant too. In Panel B we will measure the effect of ethnic diversity on business performance using more flexible (spline) functions.

The first three columns of panel A report a u-shaped relationship between the share of minorities in the team and sales. The minimum supported by these regressions lies around a share of 0.55 . The results, however, are insignificant, although the coefficients of the linear and quadratic term are significant at the 10\%-level in case of the most commonly used specification in terms of $\ln ($ sales). Columns (4) and (5) report results from least squares and median regressions with profits as the dependent variable. In column (4) neither the linear term nor the quadratic term is significantly different from zero, although the coefficients are jointly significant at the $10 \%$-level. The results from the median regression show that these findings are sensitive to outliers. The point estimates are substantially larger and both coefficients are now significant at the 5\%-level. The relationship between profits and the share of minorities seems to follow a u-shape with a minimum of 0.56 . In column (6) performance is measured as a binary indicator of positive profits. Both coefficients are significant at the 5\%-level and the share of minorities that minimizes the probability of profits being positive drops to 0.52. Finally, the last two columns report results from least square and median regressions when the dependent variable is profits per share. None of the coefficients are (jointly) significant.

$<$ Insert Table 4 about here $>$

We next fit more flexible spline functions that allow for distinct slopes above and below $55 \%$ of minorities in the team (Panel B). The cutoff at $55 \%$ is based on the results of the less flexible quadratic specifications that indicated that business performance is minimized 
at approximately this share of minorities (which also happens to be the sample average). All coefficients for the share of minorities, given that this share is above 0.55 , are positive and (with two exceptions) statistically significant. Moreover, all coefficients for the share of minorities, when lower than or equal to 0.55 , are negative and in one case significantly so. The number of teams may limit the precision of these estimates. Similar results are obtained if we run M-estimator regressions or use bootstrapped standard errors.

The results presented in this subsection show that the relationship between team performance and ethnic diversity is flat or tends to decline down to a certain threshold level and starts increasing beyond this threshold level. The specific level of this threshold varies slightly across performance measures, but is around a share of minorities of 0.55 . Only if ethnic diversity is sufficiently substantial the net effect of ethnic diversity on team performance is positive. This finding is not at odds with the idea that the costs of coordination and communication offset the benefits of complementarities and (mutual) learning in homogeneous and moderately heterogeneous teams, while the benefits of sharing and exchanging relevant knowledge outweigh these costs in more heterogeneous teams.

\subsection{Costs and benefits of ethnic diversity}

In this section we explore whether our data, collected through the questionnaires, might indeed suggest that these underlying mechanisms could drive the effect of ethnic diversity on team performance. If the variable that we employ as an indicator of a mechanism is unrelated to the share of ethnic minorities then we can safely conclude that this mechanism will not explain our findings. On the other hand, if we find a relationship between a certain mechanism and ethnic diversity then this mechanism potentially contributes to the explanation of our results. However, for the mechanism to actually explain our findings, it also needs to have a significant impact on team performance. Unfortunately, we cannot conceive of a research design (including ours) that allows testing this. The variable of interest is endogenous and we lack exogenous variation to identify its causal impact. ${ }^{18}$ In what follows, we first consider the costs and then the benefits.

For communication and coordination, we expect that moderately heterogeneous teams incur higher costs of communication and coordination than teams that are homogeneous or heterogeneous in terms of ethnicity. We measure coordination and communication costs in terms of a team's atmosphere and personal conflicts (see Earley and Mosakowski, 2000; Richard et al., 2004). Teams' atmosphere is administered by asking students to rate the atmosphere within their team on a 5-points scale in the posttreatment survey. Likewise, conflicts in the team are surveyed by asking students to what extent there was conflict or disagreement between team members about personal matters (that are not taskrelated). More personal conflicts and a worse team atmosphere are expected to result from worse communication and coordination due to, for example, subgrouping along ethnic lines, distrust or stereotyping.

\footnotetext{
${ }^{18}$ Including the regressor of interest as an additional control next to ethnic diversity would introduce a 'bad controls' problem and render the coefficients uninterpretable (see Angrist and Pischke, 2008).
} 
In line with Alesina and La Ferrara (2005), we find that homogeneous and moderately heterogeneous teams tend to experience less conflicts than heterogeneous teams (not tabulated). However, this relationship is only marginally significant. Moreover, the data indicate that teams' atmosphere and ethnic diversity are not significantly related. In sum, the data do not suggest that communication and coordination cost might drive our main finding.

For the benefits, we expect a positive relationship between ethnic diversity and business performance due to more complementarities and learning in ethnically diverse teams. We measure learning in terms of the development in seven knowledge areas that are relevant for successful entrepreneurship: business, management, entrepreneurship, strategy, organization, administration and leadership (see Minnitti and Bygrave, 2001; Karlan and Valdivia, 2011). For each of these knowledge areas, the indicator of individual learning is the difference between the self-assessed level in the posttreatment and pretreatment questionnaire.

Table 5 reports results from least squares regressions (panel A) and spline functions (panel B) of learning in different knowledge areas on ethnic diversity. Panel A shows a Ushaped relationship between the share of minorities and team-average learning, especially for the development of knowledge in business, entrepreneurship and leadership. Spline functions in panel B (cutoff again at a share of minorities of 0.55 ) indicate that the relationship between learning and share of minorities is flat or declines down to a threshold level of 0.55 and starts increasing beyond this threshold level. Hence, on average, members of ethnic heterogeneous teams learn more than members of homogeneous and moderately heterogeneous teams. Additional regressions at the individual level, that we run separately for students of Dutch and non-Dutch ethnicity, show that the learning benefits of more ethnic diversity accrue to similar extents to both groups. Moreover, and probably as an explanatory factor of the higher learning levels in more diverse teams, the data show that ethnically diverse teams enter the entrepreneurship program at the start with a more diverse pool of relevant knowledge than less heterogeneous teams (see Lazear, 1999). Table 6 shows that complementarities between team members and the coefficients of variation of business, entrepreneurship and leadership knowledge at baseline are larger in ethnically diverse teams. ${ }^{19}$

$<$ Insert Table 5 about here $>$

All in all, based on these results we cannot reject the idea that ethnic diversity benefits (mutual) learning and heterogeneous knowledge, possibly leading to better team performance. This finding is partly consistent with the theoretical ideas formulated in the introduction. Ethnically diverse teams have a more diverse pool of relevant knowledge and (possibly based on this) experience more mutual learning and achieve better results.

\footnotetext{
${ }^{19}$ The note to Table 6 discusses how we measure complementarities and heterogeneity in the relevant knowledge dimensions.
} 
However, we do not find support for the idea that moderately heterogeneous teams incur higher costs of coordination and communication.

$<$ Insert Table 6 about here $>$

\subsection{Robustness}

Robustness checks in this subsection are conducted by using a segmented approach (with teams of low, moderate and high ethnic diversity) and including control variables such as student and team characteristics.

Table A2 in the Appendix reports results from regressions of the various business outcomes on teams of low ethnic diversity (share of minorities below 0.45 ), moderate ethnic diversity (share of minorities between 0.45 and 0.65 ) and high ethnic diversity (share of minorities above 0.65). Panel A shows that in a dummy variable framework business performance is lower for teams of low and moderate ethnic diversity relative to teams of high ethnic diversity, although the number of teams may slightly limit the precision of these estimates. Spline functions in panel B indicate a similar pattern in which the effect of ethnic diversity on business performance is only positive for teams of high ethnic diversity.

As a second robustness check, we include all possible control variables discussed before. Control variables are not included all at the same time due to the limited number of observations. We restrict the analyses to specifications with (ln)sales, profits, the binary indicator of positive profits and profits per share, i.e., specifications (3), (4), (6) and (7) in Table 4. Table A3 in the Appendix shows that, separately for polynomial specifications and spline functions, none of the previous results was affected systematically by controlling for (i) team-average background characteristics of students, (ii) field of study, or (iii) other team characteristics such as size and the number of different countries of origin.

\section{Discussion and conclusion}

This paper shows evidence of a positive impact of ethnic diversity on team performance, although only starting at a certain turning point at which at least half of the team is ethnically diverse. Before this turning point the relationship is flat or slightly negative. Hence, only if ethnic diversity is sufficiently substantial the net effect of ethnic diversity on team performance is positive. In line with theoretical predictions (Lazear, 1999), our data suggest that ethnic heterogeneous teams benefit from a more diverse pool of relevant knowledge facilitating (mutual) learning.

Our study was motivated by the fact that many decisions in organizations are nowadays assigned to teams (Hamilton et al., 2003) that become increasingly diverse due to the changing composition of Western populations (e.g., Ozgen et al., 2011b). One of the most salient and relevant dimensions of team heterogeneity is ethnicity (Alesina and La Ferrara, 2005). Until today, however, studies analyzing the causal effect of ethnic diversity on team performance in the longer run have been scarce. 
We have tried to fill this gap in the empirical literature by conducting a randomized field experiment. The field experiment was conducted in the context of a worldwide leading entrepreneurship education program in one of the largest colleges in Amsterdam. The program is executed as a part of the curriculum of their international business program. Real companies are founded in identical circumstances by 45 teams of approximately 12 students. The student population consists of $55 \%$ students with a non-Dutch ethnicity from 53 different countries of origin. As outside researchers, we were allowed to exogenously vary the ethnic composition of otherwise randomly composed teams. Since the program requires students to deliver annual reports, we could measure their performance in terms of sales, profits and profits per share. All in all, this is a genuinely interesting opportunity to measure the longer term effect of ethnic diversity on team performance in realistic though controlled circumstances.

Several limitations pertain to this study. There are discrepancies between the business teams in our study and teams in the workplace. Individuals in our teams are relatively young, lack serious labor market experience and some of the teams have unprecedented high degrees of ethnic diversity. These characteristics might, to some extent, limit the external validity of our study. Moreover, although advantageous for the internal validity of our study, the random composition of teams is probably not entirely representative of common practice in business. Finally, our experimental design does not allow for a causal interpretation of mechanisms such as (mutual) learning that lead to higher performance of ethnic heterogeneous teams.

Nevertheless, teams' truly joint task with strong incentives to maximize shareholder value of a real company in which team members have time to establish roles and observations of other members closely resembles the functioning of teams in business practice. Given the upcoming increase of the share of minorities in the labor force it is likely that any team in the corporate world will become more and more diverse in terms of ethnicity. Our study might provide a realistic preview of the impact that a high degree of ethnic diversity may have on the performance of teams. 


\section{References}

Akerlof, G. and Kranton, R. (2005). Identity and the economics of organizations. The Journal of Economic Perspectives, 19(1):9-32.

Alesina, A. and La Ferrara, E. (2005). Ethnic diversity and economic performance. Journal of Economic Literature, 43(3):762-800.

Allen, J., van Breugel, G., Coenen, J., Fouarge, D., Meng, C., Ramaekers, G., van Dijk, J., and Venhorst, V. (2009). Afgestudeerden van het hbo tijdens een crisis: geen verloren generatie. Den Haag, HBO-raad.

Angrist, J. and Lang, K. (2004). Does school integration generate peer effects? evidence from boston's metco program. American Economic Review, pages 1613-1634.

Angrist, J. D. and Pischke, J. (2008). Mostly harmless econometrics: An Empiricist's Companion. Princeton University Press.

Aslund, O., Edin, P., and Fredriksson, P. (2011). Peers, neighborhoods, and immigrant student achievement: Evidence from a placement policy. American Economic Journal: Applied Economics, 3(2):67-95.

Bernstein, R. and Edwards, T. (2008). An older and more diverse nation by midcentury. US Census Bureau, Washington, DC. Retrieved on January, 6:2009.

Blau, P. (1977). Inequality and heterogeneity: A primitive theory of social structure. Free Press New York.

Boisjoly, J., Duncan, G., Kremer, M., Levy, D., and Eccles, J. (2006). Empathy or antipathy? the impact of diversity. The American economic review, 96(5):1890-1905.

Card, D. and Rothstein, J. (2007). Racial segregation and the black-white test score gap. Journal of Public Economics, 91(11-12):2158-2184.

Carter, D., D'Souza, F., Simkins, B., and Simpson, G. (2010). The gender and ethnic diversity of us boards and board committees and firm financial performance. Corporate Governance: An International Review, 18(5):396-414.

Charness, G., Rigotti, L., and Rustichini, A. (2007). Individual behavior and group membership. The American economic review, 97(4):1340-1352.

Chen, Y. and Li, S. (2009). Group identity and social preferences. The American Economic Review, 99(1):431-457.

Dugar, S. and Shahriar, Q. (2010). Group identity and the moral hazard problem: Evidence from the field. Working Papers. 
Earley, P. and Mosakowski, E. (2000). Creating hybrid team cultures: An empirical test of transnational team functioning. Academy of Management Journal, pages 26-49.

Goldberg, L. R. (1990). An alternative description of personality: The big five factor structure. Journal of Personality and Social Psychology, 59(6):1216-1229.

Hamilton, B., Nickerson, J., and Owan, H. (2003). Team incentives and worker heterogeneity: An empirical analysis of the impact of teams on productivity and participation. Journal of Political Economy, 111(3):465-497.

Hamilton, B., Nickerson, J., and Owan, H. (2004). Diversity and productivity in production teams. Unpublished working paper.

Hansen, Z., Owan, H., and Pan, J. (2006). The impact of group diversity on performance and knowledge spillover-An experiment in a college classroom. NBER Working Paper.

Hanushek, E., Kain, J., and Rivkin, S. (2009). New evidence about brown v. board of education: The complex effects of school racial composition on achievement. Journal of Labor Economics, 27(3):349-383.

Hartog, J. (2011). 9. ethnic minorities in the netherlands. Ethnic Diversity in European Labor Markets: Challenges and Solutions, page 198.

HBO-raad (2010). Feiten en cijfers: Afgestudeerden en uitvallers in het hoger beroepsonderwijs. HBO-raad, Vereniging van Hogescholen.

Hoogendoorn, S., Oosterbeek, H., and Praag, M. (2011). The impact of gender diversity on the performance of business teams: Evidence from a field experiment. Tinbergen Institute Discussion Papers.

Hoxby, C. (2000). Peer effects in the classroom: Learning from gender and race variation. NBER Working Paper.

JA Europe annual report (2009). Annual report 2008-2009. Junior Achievement Europe.

JA Worldwide annual report (2009). Annual report 2008-2009. Junior Achievement Worldwide.

Karlan, D. and Valdivia, M. (2011). Teaching entrepreneurship: Impact of business training on microfinance clients and institutions. Review of Economics and Statistics, forthcoming.

Lazear, E. (1999). Globalisation and the market for team-mates. The Economic Journal, 109(454):15-40.

Lee, N. and Nathan, M. (2011). Does cultural diversity help innovation in cities: evidence from london firms. 
Leonard, J. and Levine, D. (2006). Diversity, discrimination, and performance. Institute for Research on Labor and Employment, Working Paper Series.

Mateos, P. (2007). A review of name-based ethnicity classification methods and their potential in population studies. Population, Space and Place, 13(4):243-263.

Minnitti, M. and Bygrave, W. (2001). A dynamic model of entrepreneurial learning. Entrepreneurship Theory \& Practice, 25:5-16.

Montalvo, J. and Reynal-Querol, M. (2005). Ethnic diversity and economic development. Journal of Development economics, 76(2):293-323.

Morgan, J. and Vardy, F. (2009). Diversity in the workplace. The American Economic Review, 99(1):472-485.

Oosterbeek, H., Van Praag, M., and IJsselstein, A. (2010). The impact of entrepreneurship education on entrepreneurship skills and motivation. European Economic Review, 54(3):442-454.

Ottaviano, G. and Peri, G. (2006). The economic value of cultural diversity: evidence from us cities. Journal of Economic Geography, 6(1):9-44.

Ozgen, C., Nijkamp, P., and Poot, J. (2011a). Immigration and innovation in european regions. IZA Discussion Paper No. 5676 .

Ozgen, C., Nijkamp, P., and Poot, J. (2011b). The impact of cultural diversity on innovation: Evidence from dutch firm-level data. IZA Discussion Papers.

Parker, S. C. (2009). The Economics of Entrepreneurship. Cambridge University Press.

Parrotta, P., Pozzoli, D., and Pytlikova, M. (2010). Does labor diversity affect firm productivity? Working Papers.

Prat, A. (2002). Should a team be homogeneous? European Economic Review, 46(7):11871207.

Richard, O., Barnett, T., Dwyer, S., and Chadwick, K. (2004). Cultural diversity in management, firm performance, and the moderating role of entrepreneurial orientation dimensions. The Academy of Management Journal, pages 255-266.

Zhao, H. and Seibert, S. (2006). The Big Five personality dimensions and entrepreneurial status: A meta-analytical review. Journal of Applied Psychology, 91:259-271.

\section{Appendix A}

$<$ insert tables A1-A3 about here $>$ 


\section{Figures and tables}

Table 1. Descriptive statistics of ethnicity

\begin{tabular}{|c|c|c|c|}
\hline A: Ethnicity (team level) & Mean & SD & Min \\
\hline Share of minorities & 0.55 & $\overline{0.16}$ & $\overline{0.20}$ \\
\hline Number of different countries of origin & 6.04 & 1.82 & 3.00 \\
\hline
\end{tabular}

B: Ethnicity ( $\approx$ continent $)$

Netherlands (native)

Fraction

North America / Oceania

0.45

Central and South America

0.01

0.15

Formerly Communist Countries

0.02

Muslim Countries

0.17

East Asia

0.06

Asia

0.04

Africa

0.03

Other European Countries

0.07

C: Ethnic minority students with number of team members from the same country of origin*

\begin{tabular}{ll}
\hline 0 & 0.70 \\
1 & 0.19 \\
2 & 0.05 \\
$\geqslant 3$ & 0.06
\end{tabular}

Fraction

Note: Ethnic minority students are from the following countries of origin: North America / Oceania, Australia, Canada, United States; Central and South America, Antilles, Argentina, Barbados, Brazil, Colombia, Costa Rica, Cuba, Dominican Republic, Guyana, Honduras, Jamaica, Peru, Surinam; Formerly Communist Countries, Russia and other East European countries; Muslim Countries, Afghanistan, Algeria, Egypt, Eritrea, Guinea, Indonesia, Iran, Iraq, Malaysia, Morocco, Nigeria, Pakistan, Palestine, Somalia, Tunisia, Turkey; East Asia, China, Hong Kong, Japan; Asia, other Asian countries not included in categories of East Asia and Muslim Countries (India, Laos, Philippines, Singapore, Vietnam); Africa, other African countries not included in category of Muslim Countries (Angola, Cameroon, Cape Verde, Gabon, Ghana, Kenya, South Africa); Other European Countries, other European countries not included in category of Formerly Communist Countries (Germany, Israel and other West European countries). *Ethnic minority students in 2 teams have respectively 4 and 6 team members from the same country of origin. Excluding these teams from the sample does not change the main results. 


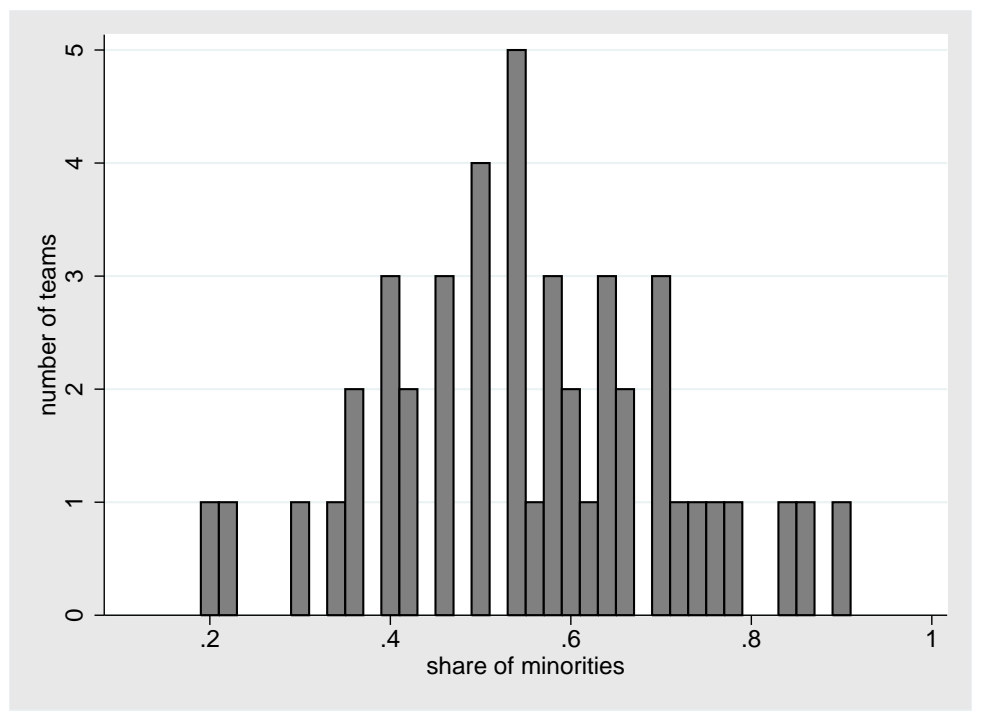

Figure 1. Frequency of share of minorities per team

Table 2. Descriptive statistics of individual and team characteristics

\begin{tabular}{|c|c|c|c|c|c|}
\hline A: Individual level & & Mean & $\underline{\mathrm{SD}}$ & Min & $\underline{\operatorname{Max}}$ \\
\hline Background & Age & $\overline{19.37}$ & $\overline{1.99}$ & $\overline{15.98}$ & $\overline{30.92}$ \\
\hline \multirow[t]{2}{*}{ characteristics } & Gender (dummy $=1$ if female) & 0.44 & 0.50 & 0.00 & 1.00 \\
\hline & Grade point average & 6.46 & 0.24 & 6.05 & 7.23 \\
\hline \multirow[t]{5}{*}{ Field of study } & Business Management & 0.44 & 0.50 & 0.00 & 1.00 \\
\hline & Management & 0.11 & 0.31 & 0.00 & 1.00 \\
\hline & Trade Management Asia & 0.19 & 0.39 & 0.00 & 1.00 \\
\hline & Business Languages & 0.21 & 0.41 & 0.00 & 1.00 \\
\hline & Financial Management & 0.05 & 0.22 & 0.00 & 1.00 \\
\hline Entrepreneurial & Business & 2.66 & 0.88 & 1.00 & 5.00 \\
\hline \multirow[t]{6}{*}{ knowledge } & Management & 2.91 & 0.93 & 1.00 & 5.00 \\
\hline & Entrepreneurship & 2.71 & 0.98 & 1.00 & 5.00 \\
\hline & Strategy & 2.71 & 0.97 & 1.00 & 5.00 \\
\hline & Organization & 2.71 & 0.98 & 1.00 & 5.00 \\
\hline & Administration & 2.62 & 0.99 & 1.00 & 5.00 \\
\hline & Leadership & 3.14 & 0.98 & 1.00 & 5.00 \\
\hline B: Team level & & Mean & $\underline{\mathrm{SD}}$ & $\underline{\text { Min }}$ & Max \\
\hline Characteristics & Size (at baseline) & $\overline{12.22}$ & $\overline{2.09}$ & $\overline{8.00}$ & $\overline{16.00}$ \\
\hline \multirow[t]{2}{*}{ and processes } & Conflicts & 2.23 & 0.59 & 1.00 & 3.67 \\
\hline & Atmosphere & 3.53 & 0.55 & 2.33 & 4.83 \\
\hline Business & Sales (euro) & 841.25 & 699.00 & 0.00 & 4209.49 \\
\hline \multirow[t]{3}{*}{ performance } & Profit (euro) & -69.17 & 317.57 & -1016.36 & 477.15 \\
\hline & $\operatorname{Pr}($ Profit $)>0$ & 0.51 & 0.51 & 0.00 & 1.00 \\
\hline & Profit/share (euro) & -0.51 & 6.42 & -15.48 & 15.64 \\
\hline
\end{tabular}


Table 3. Randomization checks at the individual and team level

\begin{tabular}{llcccc}
\hline \multicolumn{1}{c}{ A: Individual level } & \multicolumn{2}{c}{ Share of minorities } & & \multicolumn{2}{c}{ Share of minorities } \\
\cline { 3 - 5 } Background & Age & Native (Dutch) students & & Ethnic minority students \\
characteristics & Gender & 1.246 & $(0.745)$ & $-1.930^{* *}$ & $(0.806)$ \\
& Grade point average & $-0.502^{* * *}$ & $(0.172)$ & -0.074 & $(0.215)$ \\
Field of study & -0.029 & $(0.089)$ & 0.159 & $(0.109)$ \\
& Business Management & -0.246 & $(0.500)$ & -0.621 & $(0.442)$ \\
& Management & -0.118 & $(0.329)$ & -0.199 & $(0.199)$ \\
& Trade Management Asia & $0.668^{* *}$ & $(0.296)$ & $0.947^{* *}$ & $(0.418)$ \\
& Business Languages & -0.466 & $(0.420)$ & -0.277 & $(0.345)$ \\
& Financial Management & 0.162 & $(0.119)$ & 0.150 & $(0.187)$
\end{tabular}

B: Team level (average)

\begin{tabular}{|c|c|c|c|}
\hline Background & Age & -0.252 & $(0.462)$ \\
\hline \multirow[t]{2}{*}{ characteristics } & Gender & -0.231 & $(0.158)$ \\
\hline & Grade point average & -0.051 & $(0.058)$ \\
\hline \multirow[t]{5}{*}{ Field of study } & Business Management & -0.472 & $(0.434)$ \\
\hline & Management & -0.062 & $(0.240)$ \\
\hline & Trade Management Asia & $0.833^{* *}$ & $(0.348)$ \\
\hline & Business Languages & -0.453 & $(0.399)$ \\
\hline & Financial Management & 0.154 & $(0.142)$ \\
\hline Team characteristics & Team size & 1.791 & $(1.798)$ \\
\hline
\end{tabular}

Note: In panel A each coefficient comes from a regression at the individual level of the row variable on the column variable, separately for native (Dutch) and ethnic minority students. In panel B each coefficient comes from a regression at the team level of the row variable on the column variable. Robust standard errors in parentheses. $* * * / * * / *$ denotes significance at the $1 \% / 5 \% / 10 \%$-level. 


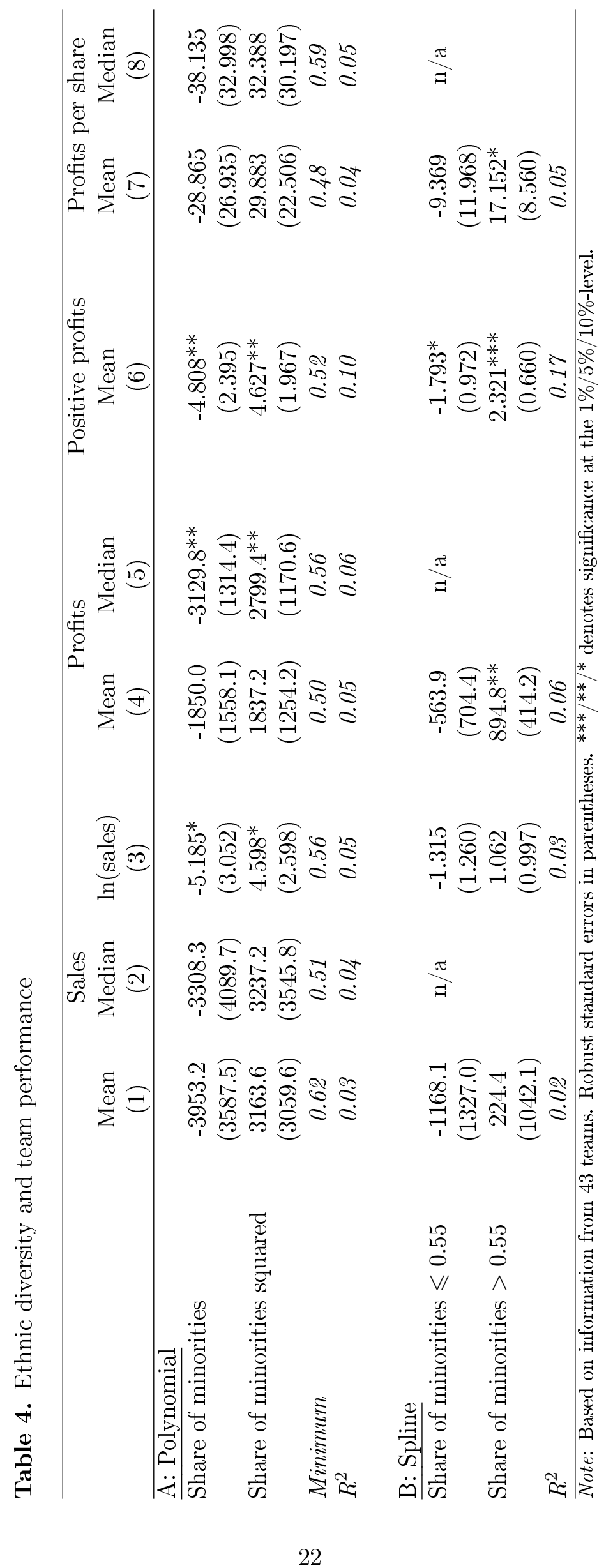




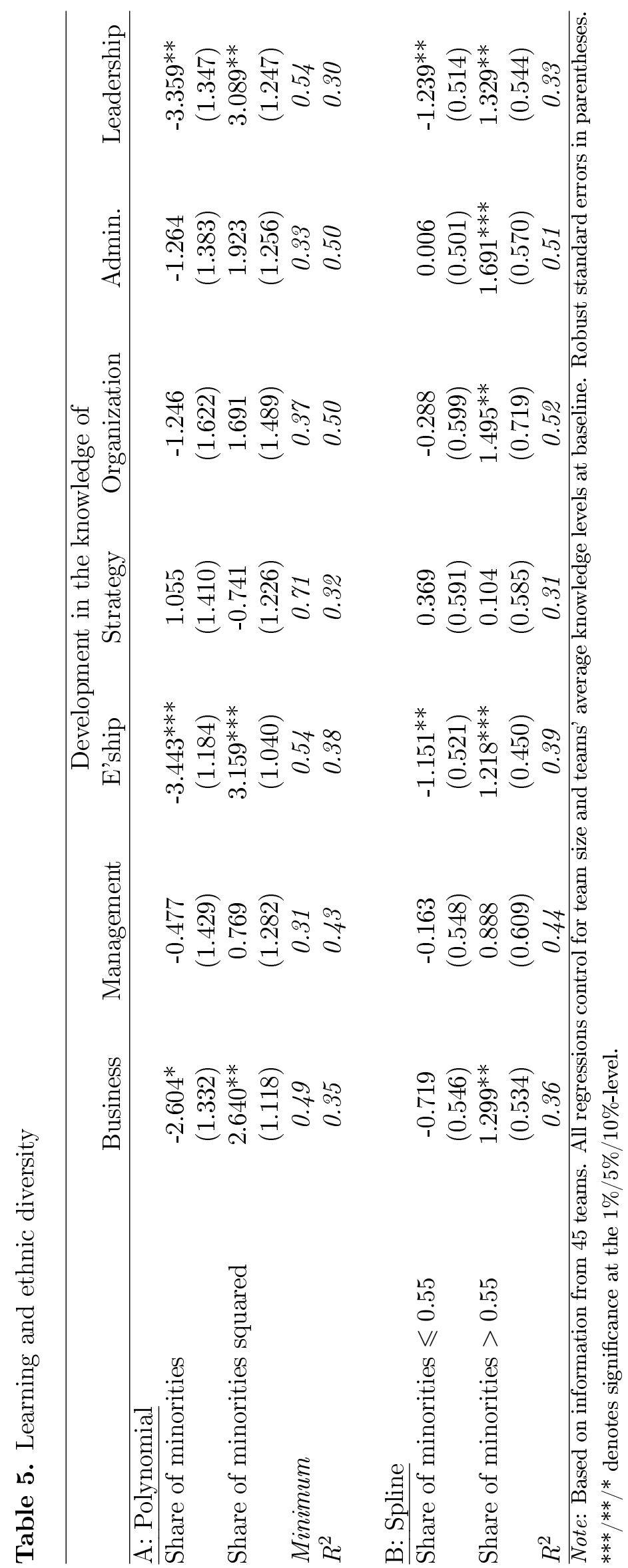


Table 6. Complementarities and diversity in relevant knowledge

\begin{tabular}{lcccc}
\hline & Complementarities & \multicolumn{3}{c}{ Diversity in knowledge of } \\
& in relevant knowledge & Business & E'ship & Leadership \\
\hline A: Polynomial & $-4.454^{* *}$ & -0.320 & -0.697 & $-0.589^{*}$ \\
\hline Share of minorities & $(2.042)$ & $(0.386)$ & $(0.439)$ & $(0.295)$ \\
Share of minorities squared & $4.107^{* *}$ & 0.305 & $0.712^{*}$ & $0.495^{*}$ \\
& $(1.702)$ & $(0.333)$ & $(0.377)$ & $(0.253)$ \\
Minimum & 0.54 & 0.52 & 0.49 & 0.59 \\
$R^{2}$ & 0.35 & 0.35 & 0.21 & 0.28 \\
& & & & \\
B: Spline & & & & \\
Share of minorities $\leqslant 0.55$ & -1.211 & -0.107 & -0.175 & -0.185 \\
& $(0.813)$ & $(0.146)$ & $0.150)$ & $(0.116)$ \\
Share of minorities $>0.55$ & $1.338^{* *}$ & 0.136 & $0.350^{* *}$ & 0.100 \\
& $(0.650)$ & $(0.136)$ & $(0.146)$ & $(0.102)$ \\
$R^{2}$ & 0.34 & 0.35 & 0.22 & 0.27 \\
\hline
\end{tabular}

Note: Based on information from 45 teams. A diverse pool of relevant knowledge at the start of the entrepreneurship program is operationalized by: (i) complementarities between the self-assessed knowledge that team members have in business, entrepreneurship and leadership, and (ii) the coefficients of variation of business, entrepreneurship and leadership knowledge in teams at baseline. Complementarities are constructed by first standardizing all three knowledge dimensions, subsequently computing the teams' maximum for each knowledge dimension, and then determining the teams' minimum of the maximums of all three knowledge dimensions. All regressions control for team size and teams' average knowledge of business, entrepreneurship and leadership at baseline. Robust standard errors in parentheses. ${ }^{* * *} / * * / *$ denotes significance at the $1 \% / 5 \% / 10 \%$-level. 
Table A1: Team characteristics

\begin{tabular}{|c|c|c|c|c|c|c|c|}
\hline$\#$ & Name & $\begin{array}{c}\text { Team } \\
\text { size }\end{array}$ & $\begin{array}{c}\text { Share of } \\
\text { minorities }\end{array}$ & $\begin{array}{l}\text { Sales } \\
\text { (euro) }\end{array}$ & $\begin{array}{l}\text { Profits } \\
\text { (euro) }\end{array}$ & $\begin{array}{c}\text { Profits } \\
\text { per share }\end{array}$ & Description of product/service \\
\hline 1 & A-Card & 16 & 0.50 & 1236.15 & -848.05 & -11.78 & Discount card for Amsterdam nightlife \\
\hline 2 & A'dam Gadgets & 12 & 0.45 & 534.12 & -41.40 & -0.47 & USB hot plate for coffee, tea, etc. \\
\hline 3 & Appie & 11 & 0.40 & 454.75 & 149.86 & 3.00 & Apple-shaped box to preserve apples \\
\hline 4 & Aqua de Coctail & 12 & 0.58 & 1130.47 & -305.94 & -3.12 & Comprehensive cocktail shaker set \\
\hline 5 & ArtEco Bags & 11 & 0.60 & 912.00 & -401.69 & -7.44 & Durable give-away bag for clothes stores \\
\hline 6 & BubbleMania & 11 & 0.70 & 503.00 & -61.79 & -1.34 & Multifunctional protective key chain \\
\hline 7 & D'Wine & 9 & 0.63 & 740.00 & -55.00 & -1.62 & Bottles of wine \\
\hline 8 & Eastern Green & 14 & 0.69 & 513.00 & 105.51 & 2.93 & Engravable text bean that grows a plant \\
\hline 9 & Escapade Inc & 9 & 0.22 & 592.55 & -111.30 & -3.09 & Tube clip for sealing food, toiletry, etc. \\
\hline 10 & eyeBMA & 16 & 0.50 & 557.50 & 124.66 & 3.90 & Package with easy-to-use eye shadow \\
\hline 11 & Firefly & 12 & 0.20 & 2225.65 & 293.62 & 3.67 & Ascending fire lantern for celebrations \\
\hline 12 & Fl!pthat & 13 & 0.64 & 455.00 & 214.88 & 9.77 & Redecorating already existing websites \\
\hline 13 & Ginger & 12 & 0.58 & 976.50 & -106.81 & -2.14 & Multifunctional solar energy charger \\
\hline 14 & Himitsu & 10 & 0.86 & 775.00 & 36.00 & 0.86 & $\mathrm{n} / \mathrm{a}$ \\
\hline 15 & I-Care & 15 & 0.54 & 1204.45 & 477.15 & 11.36 & Beauty products with Dead Sea minerals \\
\hline 16 & iJoy & 14 & 0.64 & 1952.85 & 93.56 & 1.44 & Wristband with USB storage capacity \\
\hline 17 & I-Juice & 13 & 0.54 & 1255.38 & -38.54 & -0.42 & Pocket-size lightweight mobile charger \\
\hline 18 & IMSC & 11 & 0.55 & 625.00 & -390.00 & -7.41 & $\mathrm{n} / \mathrm{a}$ \\
\hline 19 & iShield & 11 & 0.50 & 4209.49 & 129.76 & 2.20 & Invisible protective shield for iPhones \\
\hline 20 & KISBag & 9 & 0.57 & 205.48 & -117.02 & -3.90 & Tiny foldable bag to replace plastic bags \\
\hline 21 & Laservibes & 11 & 0.40 & 130.00 & -228.90 & -4.32 & Organizing lasershows for companies \\
\hline 22 & Mengelmoes & 10 & 0.71 & 941.50 & 63.14 & 1.24 & Easy-to-wear telephone charger device \\
\hline 23 & My-Buddy & 12 & 0.45 & 297.00 & -58.33 & -2.65 & USB doll for kids that reflects emoticons \\
\hline 24 & Nine2Five & 12 & 0.60 & 235.45 & -1016.36 & -12.87 & USB hot plate for coffee, tea, etc. \\
\hline 25 & Picture Perfect & 15 & 0.54 & 260.09 & -50.87 & -1.45 & Customized t-shirts for men and women \\
\hline 26 & Pietje Plu & 12 & 0.40 & $\mathrm{n} / \mathrm{a}$ & $\mathrm{n} / \mathrm{a}$ & $\mathrm{n} / \mathrm{a}$ & Trendy umbrellas \\
\hline 27 & Pocket Memory & 16 & 0.73 & 978.94 & 103.46 & 1.20 & Business cards with USB storage capacity \\
\hline 28 & Pro'Lux & 14 & 0.54 & 378.25 & -394.90 & -9.18 & Promotional gifts with USB storage capacity \\
\hline 29 & Qwinlok & 13 & 0.42 & 340.00 & 34.61 & 0.91 & Boxer shorts for female adolescents \\
\hline 30 & Reflection & 11 & 0.36 & 889.51 & 45.43 & 0.84 & Cosmetics mirror including mascara clip \\
\hline 31 & SAME & 11 & 0.36 & 1618.35 & 152.37 & 2.15 & Comfortable unisex earwarmer \\
\hline 32 & Sappho & 8 & 0.50 & 980.00 & $\mathrm{n} / \mathrm{a}$ & $\mathrm{n} / \mathrm{a}$ & $\mathrm{n} / \mathrm{a}$ \\
\hline 33 & Sharity & 12 & 0.67 & 265.00 & -241.12 & -8.04 & Necklace with peace sign for teenagers \\
\hline 34 & ShoeTattoo & 13 & 0.77 & 270.00 & 88.32 & 1.21 & Shoe customization by graphic artists \\
\hline 35 & Student Promotion & 13 & 0.42 & 571.32 & 234.54 & 15.64 & Promotional activities for companies \\
\hline 36 & StuPill & 14 & 0.31 & 731.33 & -1011.33 & -15.48 & Comfortable Indonesian anti-RSI pillow \\
\hline 37 & Test-a-Holic & 11 & 0.45 & 728.45 & 219.77 & 4.88 & Alcohol breath tester for nightlife \\
\hline 38 & We-Do Solutions & 10 & 0.56 & 604.00 & -266.82 & -6.06 & Multifunctional trendy key chain \\
\hline 39 & We 'R U & 13 & 0.33 & 1041.11 & 49.77 & 0.89 & Compact wallet in several colors \\
\hline 40 & $\mathrm{XNG}$ & 12 & 0.90 & 1087.50 & 258.31 & 7.60 & T-shirts of "Chicks on Kicks" community \\
\hline 41 & YEN Empowered & 13 & 0.83 & 1266.67 & 33.33 & 0.71 & $\mathrm{n} / \mathrm{a}$ \\
\hline 42 & YET's Wear & 16 & 0.79 & 789.08 & -246.81 & -2.47 & Customized t-shirts of own YET-brand \\
\hline 43 & YOU & 12 & 0.64 & 0.00 & -242.41 & -6.55 & Hotel door hanger to store keys, money, etc. \\
\hline 44 & Young Legends & 9 & 0.67 & 400.00 & 59.00 & 0.84 & $\mathrm{n} / \mathrm{a}$ \\
\hline 45 & YUVA & 16 & 0.70 & 1153.00 & 294.11 & 12.79 & Engravable grain of rice in a glass covering \\
\hline
\end{tabular}




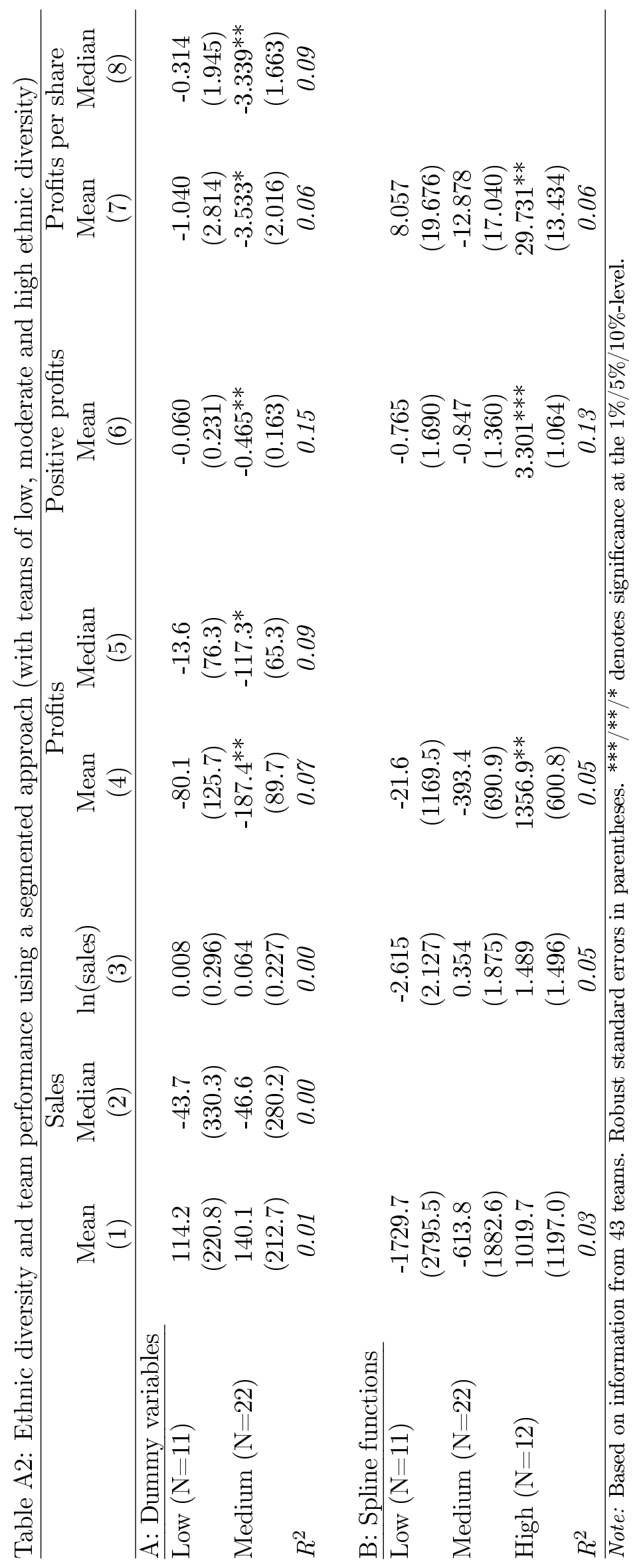




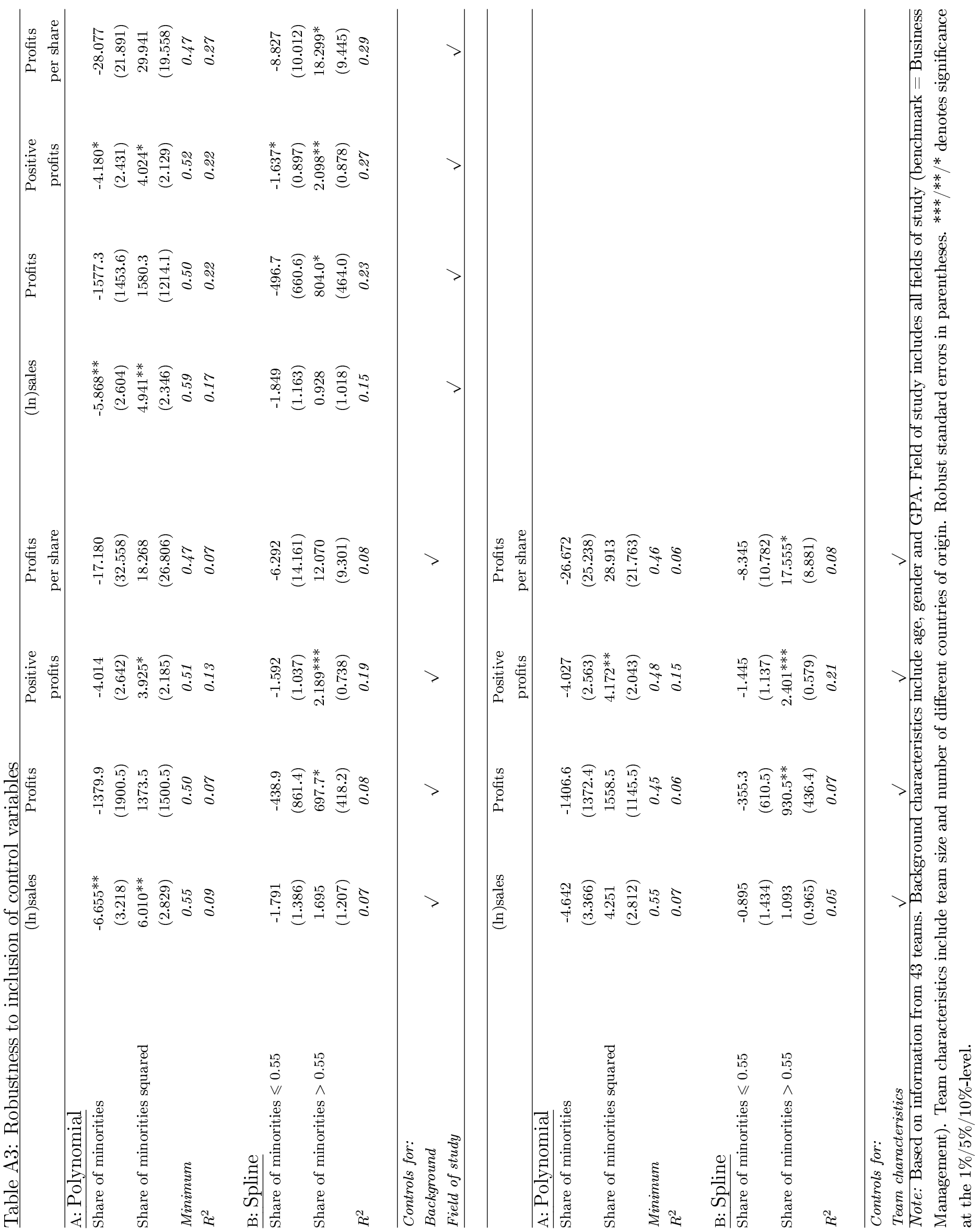

